\title{
Beyond prevalence and pattern: problematic extent of alcohol and substance use among adolescents in Ibadan South-west Nigeria
}

\author{
*Atilola $\mathrm{O}^{1,2}$, Ayinde $\mathrm{O}^{2}$, Adeitan $\mathrm{O}^{2}$
}

1. Department of Behavioural Medicine, Lagos state University College of Medicine Ikeja Lagos, Nigeria.

2. Department of Psychiatry, University College Hospital Ibadan, Nigeria

\begin{abstract}
Background: Previous research on adolescent alcohol/substance use in Nigeria had focused on the pattern of use without consideration for the extent of use. Socio-demographic correlates have also not been well explored. Information about socio-demographic correlates can also inform target-points in preventive strategies. Knowledge of the prevalence of problematic pattern of alcohol/substance use can inform the inclusion of rehabilitation strategies in intervention policies.

Objectives: To determine the prevalence, pattern and extent- as well as socio-demographic correlates -of alcohol/substance use among a cohort of adolescents in Nigeria.

Methods: Pattern and extent of alcohol/substance use was examined using the CRAFFT instrument.

Results: A total of 538 adolescents with a mean age of $15.1 \pm 1.4$ years returned completed questionnaires. 12-month prevalence of alcohol and other substance use was $21.4 \%$. About $46 \%$ of those who reported use of alcohol or any other substance had a CRAFFT score of $>2$ which suggests problematic pattern of use. Older age, male gender, parental alcohol and substance and lower than average school performance were independently associated with 12-momth use of alcohol or any other substance.

Conclusions: Adolescent alcohol and substance use is common in Nigeria and a large proportion of users show a problematic pattern of use that warrants rehabilitative intervention.

Key words: Adolescents, substance abuse, CRAFFT, Nigeria

African Health Sciences 2013; 13(3): 777 - 784 http:/ /dx.doi.org/10.4314/ahs.v13i3.37
\end{abstract}

\section{Introduction}

A predominantly youthful population ${ }^{1}$ and a low level of human development capacity ${ }^{2}$ is a social reality in Nigeria. This scenario puts the country at some distinct disadvantages in-terms of the mental health and wellbeing of child and adolescent populations. First, it will be tasking to provide the needed resources for optimal wellbeing of such large youth population in the setting of resource constraints. Second, it is conceivable that any resourceconstrained country with a teeming youth population will be highly susceptible to many unintended negative effects of globalisation like widespread adolescent substance abuse. Social and economic hardships experienced by young persons in developing countries like Nigeria had been suggested as a key factor for the rising cases of adolescent alcohol and substance use/abuse in such regions. ${ }^{3,4}$

*Corresponding author:
Dr. Olayinka Atilola
Department of Behavioural Medicine
Lagos State University College of Medicine, Ikeja
Lagos, Nigeria
Tel: +2348063867269
Email: draromedics@yahoo.com

African Health Sciences Vol 13 Issue 3 September 2013
Also, one of the most outstanding ways by which globalisation has negatively influenced the health and wellbeing of adolescents and youth in resourceconstrained countries has been through increases in alcohol and other substance use/abuse. ${ }^{4,5}$

A modest number of studies have examined the epidemiology of alcohol/substance use among adolescents in Nigeria with useful policy recommendations. ${ }^{6-12}$ However, most of these studies had focussed only on the prevalence and pattern of use without addressing the social correlates. The few that examined social correlates had focussed mainly on family-related factors while assessing the risks for adolescent alcohol/substance use. ${ }^{10,12}$ The focus on the family is understandable in view of the fact that the family-unit is a critical component of the care-environment of children which protect them from all forms of social vices ${ }^{13}$ including alcohol/substance abuse. Beyond family factors however, it has been suggested that the personal social-circumstance of adolescents can influence alcohol and substance use/abuse among them. ${ }^{14}$ Such personal social-factors may include engagement in regular physical exercise/sport, 
presence or otherwise of a chronic disabling physical condition, level of religious engagement, and school performance. These factors can confound family factors and can be additional target-points in adolescent alcohol and substance use prevention policies.

Furthermore, most of studies that have been done on the subject of adolescent alcohol and substance use in Nigeria had focused on the pattern of use (in terms of current- and lifetime-use) without assessing the presence or otherwise of problematic patterns of use, harmful use, or dependence. Focusing on adolescent alcohol and substance use pattern is a reasonable policy strategy because early onset of use is a well known harbinger of alcohol and substance use disorders in adulthood. ${ }^{15}$ As such, pattern of use among adolescents can inform strategies to prevent substance use disorders in adulthood. However, with the advent of screening instruments like the CRAFFT which can assess problematic use of alcohol and other substances among adolescents ${ }^{16}$; it is high time we began to go beyond patterns of use to include assessment of extent of problematic use that may warrant rehabilitative interventions at present. Knowledge about current problematic extent of alcohol and other substance use among young persons will help to plan rehabilitative services for them, as such extent of use can lead to permanent neuro-developmental problems ${ }^{17}$ and poor social development ${ }^{18,19}$ if unattended.

In addition, child and adolescent mental health $(\mathrm{CAMH})$ researchers recently made a call for the incorporation of mental health services into school health programmes in Nigeria. ${ }^{20}$ Establishing the prevalence of problematic alcohol and other substance use among school-going adolescents in Nigeria at this time will serve as a rationale for inclusion of rehabilitative services for such adolescents in a comprehensive school mental health policy for the country.

This study therefore aimed to determine the prevalence, pattern and correlates of alcohol and substance use among a cohort of school-going adolescents in South-West Nigeria. The sociodemographic characteristics assessed extended beyond the family factors to include personal social factors. Furthermore, the extent of use - in terms of screening for evidence of problematic pattern of use - was also assessed.

\section{Methods}

\section{Setting and sample selection}

The study was carried out in Ibadan, Nigeria. Ibadan is the third largest city in Nigeria with an estimated population of about 2.6 million spread over 11 local districts. Participants were sampled from 2 public schools within one of the 11 districts. The closest district to the domicile of the researchers was picked for convenience. All adolescents in the Senior Secondary Class 1 and 2 (corresponding with 10th and 11 th year of schooling) in the schools were sampled. A total of 587 adolescents were so sampled.

\section{Procedures}

All participants were informed and educated about the purpose and modalities of the study, first by the school counsellors and later by the investigators. The adolescents who returned self or parental consent (depending on age) were asked to complete a set of questionnaires during the break hours of the school. They were all seated in the school hall with enough space between them for privacy. The use of the hall was to prevent a low response rate. All questionnaires were available in English and in Yoruba- the most predominant local language in the region.

\section{Study instruments}

Socio-demographic questionnaire: A sociodemographic questionnaire was developed by the authors. The questionnaire enquired about general demographic variables like age, gender and family factors like marital status of parents, parental educational/occupational status, current care-giving arrangement, and parental alcohol/substance use among others. In addition, the socio-demographic questionnaire assessed diverse aspects of the personal social circumstance of the respondents. These include engagement in regular physical exercise; presence or otherwise of a chronic disabling physical condition, self reported level of religious engagement, selfreported school performance in the last 12 months and other similar data. Regular exercise/sport was described in the questionnaire as up to once in a week in the last 6 months. To assess level of religiosity, participants were asked how much their religious convictions dictated their personal life. For the purpose of assessing possible influence of religiosity on alcohol and substance use, self-reported significant influence of religion on personal choices was taken as high religiosity. School-performance were based 
on self-reports and dichotomised into above average and average/below average.

\section{The CRAFFT questionnaire}

Alcohol/substance use was assessed by the CRAFFT self-report questionnaire. ${ }^{16}$ The CRAFFT is a behavioral health screening tool for assessing levels of problematic alcohol/drug use among adolescents in the past 12 months. It consists of a series of 6 questions developed to screen adolescents for high risk alcohol and other drug use disorders simultaneously. It is capable of providing information about both pattern of use and extent of use. The response to each of the 6 questions which assesses the extent of use can either be 'yes' (1 point) or 'no' ( 0 point). A minimum score of zero and a maximum score of 6 is thereby generated for each respondent that reported 12-month use of alcohol or any other substance. A score of 2 and above is known to suggest a problematic pattern of use that may warrant rehabilitative intervention. ${ }^{16,21}$ Further details of the coinage of the questions in

CRAFFT are accessible at: http:// www.ceasarboston.org/clinicians/crafft.php.

In line with the guidelines for the translation and cultural adaptation of patient-reported outcomes measures ${ }^{22}$ the CRAFFT was adapted such that the word "car" in the phrase "ridden in a car driven by someone...." as contained in the original CRAFFT instrument was changed to "car/motorbike". This was because in the use of motorbikes is a common means of transportation in Nigeria. Some adolescents participated in the translation of the CRAFFT instrument to Yoruba to ensure the appropriateness of the language for adolescents. Other than the word "motorcycle" which was added to the instrument, both the adapted Yoruba and the back-translated versions of CRAFFT were essentially similar in wordings to the original English version.

\section{Data handling \& statistical analysis}

The data collected were analyzed using the Statistical Package for Social Sciences version 16 (SPSS - 16) soft ware. Analyses included descriptive, bivariate and multivariate statistics. Values of $\mathrm{p}<0.05$ were considered statistically significant in all analyses.

\section{Ethical considerations}

All adolescents were informed about the aims and procedures of the study. Those who were 16 years and above signed consent forms while the younger participants returned signed parental consent and personal assent forms. Ethical approval was obtained from the State Ministry of Health.

\section{Results}

A total of 538 adolescents returned completed questionnaires amounting to a $92 \%$ response rate. About $76 \%(n=412)$ took the Yoruba option while the rest opted for the English version. The mean age was $15.1 \pm 1.4$ years with a slight female preponderance $(55.6 \%)$. Among the respondents, $115(21.4 \%)$ reported using at least one substance (including alcohol) in the last 12 months. Out of this, $53(46 \%)$ had a CRAFFT score of 2 and above which suggests problematic pattern of use. This figure translates to $10 \%$ of the total sample. Other aspects of the pattern of use of alcohol and other substances among the participants are as shown in table 1.

As shown in table 2, among all other socio-demographic characteristics of participants, older age, male gender, parental alcohol and substance and lower than average school performance were independently associated with 12-momth use of alcohol or any other substance. 
Table 1: Pattern and gender distribution of alcohol and substance use among participants

\begin{tabular}{llll}
\hline Variable & N (\%) & $\begin{array}{l}\text { Gender distribution } \\
\text { (Male vs. Female) }\end{array}$ & p \\
\hline 12-month use of alcohol \& any other substance & $115(21.4)$ & $56.5 \%$ vs. $43.5 \%$ & 0.012 \\
12-month use of Alcohol & $62(11.5)$ & $65.5 \%$ vs. $34.5 \%$ & 0.001 \\
12-month use of Tobacco & $38(7.0)$ & $88 \%$ vs. $12 \%$ & $<0.001$ \\
12-month use of Marijuana/cannabis & $5(1.0)$ & $60 \%$ vs. $40 \%$ & 0.41 \\
12 month use of any other substance & $21(3.9)$ & $50.8 \%$ vs. $49.2 \%$ & 0.36 \\
- Glue & $20 \%$ & & \\
- Petrol \& other solvents & $15 \%$ & & \\
\hline
\end{tabular}

Table 2: Bivariate and multivariate associations between socio-demographic characteristics and 12month use of alcohol and other substance $(n=538)$

\begin{tabular}{|c|c|c|c|}
\hline \multirow[t]{2}{*}{ Variable } & \multirow[t]{2}{*}{$\mathrm{N}(\%)$} & \multicolumn{2}{|c|}{$\begin{array}{l}\text { 12-month use of alcohol \& other } \\
\text { substances }\end{array}$} \\
\hline & & OR $(95 \% \mathrm{CI})$ & $\begin{array}{l}\text { Adjusted OR } \\
(95 \% \mathrm{CI})^{*}\end{array}$ \\
\hline \multicolumn{4}{|l|}{ Gender } \\
\hline (Male vs. Female) & 244 (45.4) vs. $294(54.6)$ & $1.56(1.13-2.17)$ & $1.71(1.23-2.88)$ \\
\hline \multicolumn{4}{|l|}{ Age } \\
\hline ( $\leq$ median age of $15 y r s$ vs. above median age of $15 y r s)$ & $370(68.8)$ vs. $168(31.2)$ & $0.68(0.49-0.94)$ & $0.61(0.44-0.88)$ \\
\hline \multicolumn{4}{|l|}{ Regular exercise/sport } \\
\hline (Yes vs. No) & 425 (79.7) vs. $113(20.3)$ & $1.28(0.82-2.00)$ & \\
\hline \multicolumn{4}{|l|}{ Current care arrangement: } \\
\hline Living with single parents/alternative care-arrangements vs. Living with & $136(25.3)$ vs. $402(74.7)$ & $1.74(0.74-1.56)$ & \\
\hline \multicolumn{4}{|l|}{ both parents } \\
\hline \multicolumn{4}{|l|}{ Education of parents: } \\
\hline No more than elementary education for mother vs. Up to secondary & $72(13.5)$ vs. $466(86.5)$ & $1.22(0.79-1.90)$ & \\
\hline education & $49(9.4)$ vs. $489(91.6)$ & $1.28(0.78-2.11)$ & \\
\hline \multicolumn{4}{|l|}{$\begin{array}{l}\text { No more than elementary education for father vs. Up to secondary } \\
\text { education }\end{array}$} \\
\hline \multicolumn{4}{|l|}{ Employment status of parents: } \\
\hline Mother employed vs. Unemployed & 489 (91.6) vs. $49(9.4)$ & $0.90(0.52-1.56)$ & \\
\hline Father employed vs. Unemployed & 448 (84.1) vs. 90 (15.9) & $0.84(0.56-1.27)$ & \\
\hline \multicolumn{4}{|l|}{ Parental alcohol/ substance use: } \\
\hline Mother (Yes vs. No) & $24(4.5)$ vs. $514(95.5)$ & $1.81(1.05-3.12)$ & $2.00(1.81-4.77)$ \\
\hline Father (Yes vs. No) & $40(7.4)$ vs. $498(92.6)$ & $2.31(1.57-3.40)$ & $3.38(2.00-4.70)$ \\
\hline \multicolumn{4}{|l|}{ Chronic illness/ disability } \\
\hline (Yes vs. No) & 75 (14.2) vs. $463(85.8)$ & $1.52(1.08-2.37)$ & \\
\hline \multicolumn{4}{|l|}{ Self reported level of religiosity } \\
\hline (High vs. Low). & $102(19.1)$ vs. $436(80.9)$ & $0.94(0.62-1.4)$ & \\
\hline \multicolumn{4}{|l|}{ Self reported average level of school performance in the last 12 months } \\
\hline (Below average vs. Average/Above average) & $119(22.1)$ vs. $419(77.9)$ & $2.41(1.74-3.55)$ & $3.39(2.00-3.71)$ \\
\hline
\end{tabular}

* Variables included in the multivariate logistic regression analyses are those significantly associated with alcohol and other substance use. Statistically significant associations are boldfaced. All variables were dichotomized to indicate the presence or absence of the particular risk factor. In multivariate analysis, the first variable mentioned is the reference point. E.g. in A vs. $\mathrm{B}$; the reference point is $\mathrm{A}$ 


\section{Discussion}

This study evaluated the prevalence, pattern and personal socio-demographic factors that were independently associated with adolescent alcohol and substance use among a cohort of school-going adolescents in Nigeria. Results showed that about $21 \%$ of the adolescents had used alcohol or any other substance in the preceding 12-months. Recent studies from Nigeria had found similarly high prevalence of alcohol and substance use among adolescents in the country. ${ }^{9,10,23}$ Methodological differences in the duration of use assessed (current, 12-months, or lifetime) and the definition of 'substance' (inclusive of prescription drugs or not) limits the strict comparison of the prevalence of use in the current study and the previous ones. One thing that is however clear from the collective evidence is that alcohol and substance use is very common among adolescents in Nigeria.

Alcohol and tobacco in that order were the most commonly used substance among adolescents in the present study. Again, this pattern is well documented among adolescents in Nigeria. ${ }^{8-10,23}$ In fact, some studies have established that alcohol and tobacco are indeed the 'gateway drugs' among adolescents in Nigeria ${ }^{10,24}$ in line with the global pattern. ${ }^{25}$ These findings had been used to make a call for control of the availability of the 'gateway drugs' to adolescents and for more school-based education on the dangers of substance use among adolescents in Nigeria. ${ }^{9,10,23}$

Among the significant additions of the present study to the on-going discourse on adolescent alcohol and substance use in Nigeria is the identification of certain personal socio-demographic factors that are independently associated with use among adolescents. Earlier studies had focused on family related factors and had not found a consistent association. For instance, Fatoye ${ }^{12}$ found that adolescents from disrupted families were more likely to use a substance. More recently Oshodi et a ${ }^{10}$ found no association between alcohol/substance use and the prevailing care-giving arrangements of adolescent in the same region where the earlier study was conducted. Disintegrating family values and its adverse implication for censorship of adolescents' exposure to alcohol and other substance in the community has been advanced as possible explanation for lack of association between family factors and adolescent substance use in recent times. ${ }^{10}$ Globalisation is believed to have eroded the power of censure which traditional societies in low-income countries enjoyed over the conduct and preferences of children and adolescents, leading to increasing prevalence of adolescent alcohol and substance use in such countries. ${ }^{26}$ In agreement with the foregoing, the care-giving arrangement of adolescents in the current study was not significantly associated with adolescent substance use. The only family-related factor that was independently associated with adolescent alcohol and substance use in the present study was parental alcohol/substance use. This is not surprising as parental use may suggest that alcohol and other substances are available in the home environment and thus aiding initiation. Modelling and genetic factors may also play some role.

Majority of the factors that were independently associated with adolescent use of alcohol and other substances in the current study were personal factors like older age, male gender, and selfreported poor academic performance. The implication of this finding is that school-based alcohol and substance use prevention/intervention strategies should look beyond the family, to include modifiable personal factors. Specifically, schoolbased prevention programmes should be instituted early and among junior classes while intervention programmes will necessarily have to be incorporated into the programmes for senior classes.

Self reported poor academic performance was the most significant factor that was independently associated with 12-month alcohol and substance use in the current study. The relationship between alcohol/substance use and school performance can be bi-directional. It is known that adolescent alcohol and substance use can affect cognitive functions ${ }^{27}$ while the social context of alcohol and substance use can affect school engagement; ${ }^{28,29}$ both of which can in-turn lead to poor academic performance. The stress of being a low academic achiever itself can engender compensatory externalising behaviours like alcohol/substance use. Regardless of the nature and direction of the relationship between academic achievement and alcohol/substance use; school-based interventions still offers a unique opportunity to address it. ${ }^{29}$ The present study however relied solely on adolescents' self-report of school performance without verification. This was because of the logistic problems involved in getting aggregate scores of adolescents over one year for verification. Future studies may want to further examine the relationship between adolescent alcohol/substance use and school performance in Nigerian samples using verifiable measures of academic achievement. If 
such studies replicate our findings, then poor academic achievement, especially among adolescents with other risk factors, may be a marker for screening for alcohol/substance use or abuse with a view for early intervention.

There are some important negative findings in the association between personal factors and alcohol substance use among the adolescents in this study. Presence of a chronic illness or disability showed significant association at bivariate analysis but not after logistic regression. It is known that the combined task of adjusting to chronic illness/ disability and the turmoil of adolescence can be a source of exceptional stress, ${ }^{30}$ which can increase the risk of high-risk behaviours including alcohol and substance abuse. ${ }^{31}$ The current study suggests that this association may be confounded by other personal factors in the adolescent like age, gender, parental substance abuse and other personal social factors. Similarly, there was no association between self reported religiosity and alcohol/substance use in the present study. This is not in agreement with popular views that the sense of calm; connectedness with a higher being, and the moral teachings that comes with religiosity may dissuade adolescents from risky behaviours like alcohol/substance use. It is however possible that our methodology failed to measure these values of religion correctly.

An equally significant contribution of the current study to the literature on adolescent alcohol and substance use in Nigeria is the observation that almost half of the adolescents who reported 12month alcohol and other substance use had a CRAFFT score in the range of problematic use or abuse. This is the crux of the matter. Previous efforts in Nigeria at addressing the issue of adolescent alcohol and substance use had insightfully focussed on prevention of use-debut. But the current findings suggest that there is a need to expand services to include rehabilitation of adolescents who may have developed a maladaptive pattern of use of alcohol and other substances. As part of the proposed initial steps towards school-based CAMH in Nigeria, equipping teachers and school counsellors to be able to identify and appropriately refer common CAMH problems has been advocated. ${ }^{20}$ Therefore, screening for use and maladaptive pattern of use of alcohol and other substances can be combined with schoolbased use-prevention programmes. In fact, a recent study has developed protocols that incorporate interventions like motivational interviewing with classroom-based prevention programmes. ${ }^{32}$ Such programmes can be adapted into the Nigerian school setting. In addition, bilateral liaison co-operation can be established between the school counsellors and CAMH service centres/service-providers in the vicinity for the purpose of intervention. The CRAFFT is a short and easy screening instrument for adolescent alcohol and substance use disorders which can easily be administered by school counsellors.

A major strength of this study is the fact that it examined a wide array of socio-demographic correlates of alcohol/substance use among adolescents. In addition, this is the first study in Nigeria, to the best of the authors' knowledge, which examined problematic use of alcohol and substance among adolescents in Nigeria. A major limitation however is the fact the psychometric properties of the CRAFFT instrument has not been done to ascertain its usefulness. However, we made an attempt to reduce this effect by doing some cultural adaptation as reported in the methodology section. The cross-sectional nature of the study also limits the extent to which we can understand the direction of association. Finally, our sample is not representative enough for generalization of findings. Large-scale representative are therefore needed.

\section{Conclusions}

This study adds to the existing body of evidence that adolescent alcohol and substance use is common in Nigeria and that in addition, a large proportion of users show a problematic pattern of use that may warrant intervention. Furthermore, the study distinctly present evidence that personal factors plays a important roles in adolescent alcohol and substance use and should be factored into intervention strategies.

\section{Acknowledgements}

The authors wish to acknowledge the technical support provided by the International Child Mental Health Study Group in the course of this study.

\section{References}

1. Central Intelligence Agency. The World Factbook [Internet]. 2011 [cited 2012 Dec 2]. Available from: https://www.cia.gov/library/ publications/the-world-factbook/

2. UNDP. International Human Development Indicators. Nigeria country profile [Internet]. 2011 [cited 2012 Dec 2]. Available from: http:/ 
/hdrstats.undp.org/en/countries/profiles/ NGA.html

3. Blum RW, Nelson-Mmari K. The health of young people in a global context. J Adolesc Health. 2004 Nov;35(5):402-18.

4. Anderson P. Global use of alcohol, drugs and tobacco. Drug and Alcohol Review. 2006 Nov 1;25(6):489-502.

5. Jernigan DH. Extent of Global Alcohol Marketing and Its Impact on Youth, The. Contemp. Drug Probs. 2010;37:57.

6. Adelekan ML, Makanjuola AB, Ndom RJ, Fayeye JO, Adegoke AA, Amusan O, et al. 5yearly monitoring of trends of substance use among secondary school students in Ilorin, Nigeria, 1988-1998. West Afr J Med. 2001 Mar;20(1):28-36.

7. Fatoye FO, Morakinyo O. Substance use amongst secondary school students in rural and urban communities in south western Nigeria. East Afr Med J. 2002 Jun;79(6):299-305.

8. Eneh AU, Stanley PC. Pattern of substance use among secondary school students in Rivers State. Niger J Med. 2004 Mar;13(1):36-9.

9. Igwe WC, Ojinnaka N, Ejiofor SO, Emechebe GO, Ibe BC. Socio Demographic Correlates of Psychoactive Substance Abuse among Secondary School Students in Enugu, Nigeria. Europ J of Social Science. 2009;12(2):277.

10. Oshodi OY, Aina OF, Onajole AT. Substance use among secondary school students in an urban setting in Nigeria: prevalence and associated factors. Afr J Psychiatry (Johannesbg). 2010 Mar;13(1):52-7.

11. Famuyiwa O, Aina OF, Bankole-Oki OM. Epidemiology of psychoactive drug use amongst adolescents in metropolitan Lagos, Nigeria. Eur Child Adolesc Psychiatry. 2011 Jul;20(7):351-9.

12. Fatoye FO. Psychosocial correlates of substance use amongst secondary school students in south western Nigeria. East Afr Med J. 2003 Mar;80(3):154-8.

13. UNICEF. The child in the family [Internet]. UNICEF. 2004 [cited 2012 Dec 27]. Available from: http://www.unicef.org/childfamily/ index.html

14. Dielman TE, Butchart AT, Shope JT, Miller M. Environmental correlates of adolescent substance use and misuse: implications for prevention programs. Int J Addict. 1990 91;25(7A-8A):855-80.

15. Winters KC, Lee C-YS. Likelihood of developing an alcohol and cannabis use disorder during youth: association with recent use and age. Drug Alcohol Depend. 2008 Jan 1;92(1-3):239_ 47.

16. Knight JR, Shrier LA, Bravender TD, Farrell M, Vander Bilt J, Shaffer HJ. A new brief screen for adolescent substance abuse. Arch Pediatr Adolesc Med. 1999 Jun;153(6):591-6.

17. Masten AS, Faden VB, Zucker RA, Spear LP. Underage Drinking: A Developmental Framework. Pediatrics. 2008 Apr 1;121(Supplement):S235-S251.

18. Feldstein SW, Miller WR. Substance use and risktaking among adolescents. Journal of Mental Health. 2006 Jan;15(6):633-43.

19. Storr CL, Accornero VH, Crum RM. Profiles of current disruptive behavior: association with recent drug consumption among adolescents. Addict Behav. 2007 Feb;32(2):248-64.

20. Bella T, Omigbodun O, Atilola O. Towards School Mental Health in Nigeria: Baseline Knowledge and Attitudes of Elementary School Teachers. Adv Sch Ment Health Promot. 2011;4(3):55-62.

21. Knight JR, Sherritt L, Shrier LA, Harris SK, Chang G. Validity of the CRAFFT substance abuse screening test among adolescent clinic patients. Arch Pediatr Adolesc Med. 2002 Jun;156(6):607-14.

22. Wild D, Grove A, Martin M, Eremenco S, McElroy S, Verjee-Lorenz A, et al. Principles of good practice for the translation and cultural adaptation process for patient-reported outcomes (PRO) measures: report of the ISPOR task force for translation and cultural adaptation. Value in health. 2005;8(2):94-104.

23. Omokhodion F, Faseru B. Perception of cigarette smoking and advertisement among senior secondary school students in Ibadan, Southwestern Nigeria. West Afr J Med. 2007;26(3):206-9.

24. Omigbodun O, Babalola O. Psychosocial Dynamics of Psychoactive Substance Misuse among Nigerian Adolescents. Annals Afri Med. 2004;3(3):111-5.

25. McArdle P. Substance abuse by children and young people. Arch Dis Child. 2004 Aug;89(8):701-4. 
26. Sharan P. Prevention of Substance Abuse among Adolescents in Low-and Middle-Income countries. J. Indian Assoc. Child Adolesc. Ment. Health. 2006;2(4):96-9.

27. Tapert SF, Brown SA. Neuropsychological correlates of adolescent substance abuse: fouryear outcomes. J Int Neuropsychol Soc. 1999 Sep;5(6):481-93.

28. Lynskey M. Substance Use and Educational Attainment. Addiction. 2006;101(12):1684-5.

29. Harrington Godley S. Substance use, academic performance and the village school. Addiction. 2006 Dec;101(12):1685-8.
30. Rolland JS. Chronic Illness and the Life Cycle:A Conceptual Framework. Family Process. 1987 Jun;26(2):203-21.

31. Everett Jones S, Lollar DJ. Relationship between physical disabilities or long-term health problems and health risk behaviors or conditions among US high school students. J Sch Health. 2008 May;78(5):252-257; quiz 298-299.

32. Barnett E, Spruijt-Metz D, Unger JB, Sun P, Rohrbach LA, Sussman S. Boosting a teen substance use prevention program with motivational interviewing. Subst Use Misuse. 2012 Mar;47(4):418-28. 